\title{
Occurrence of Ibuprofen in the Waters of the Bengal River in Nova Friburgo
}

\author{
Carla Mariah Oliveira Fujimaki ${ }^{1}$ and Robson Roney Bernardo ${ }^{2}$ \\ 1. Biophysics Institute Carlos Chagas Filho, Federal University of Rio de Janeiro, Rio de Janeiro 21941-902, Brazil \\ 2. Campus Xerem, Federal University of Rio de Janeiro, Duque de Caxias 25245-390, Brazil
}

\begin{abstract}
The increasing use of pharmaceuticals throughout the world is generating a new environmental problem where they are found in low concentrations, but the long-term risks to various organisms, as well as human health, are not yet known. These drugs, as well as their metabolites, are introduced into aquatic environments through excretions or discharges and may cause the same exposure as POPs (Persistent Organic Pollutants) due to its continued entry into the environment. The aim of this work is to develop a sensitive analytical method for the detection of ibuprofen and its metabolites in the Bengalas river that crosses the city of Nova Friburgo in the state of Rio de Janeiro. Three collection points were analyzed monthly in the river from its source, as well as points of treated water throughout the city. The samples were collected monthly and lyophilized. Subsequently, they were subjected to a solid phase extraction (silica) with the solvent dichloromethane: hexane $(1: 1 ; \mathrm{v} / \mathrm{v})$. The samples were evaporated over a nitrogen atmosphere and subjected to a LC-MS (Liquid Chromatography with Mass Spectrometry) with 5\% acetic acid gradient: acetonitrile as the mobile phase. In the search for drugs, there were found ions and fragments of ibuprofen (m/z 206, 205, 177) that were sought and compared to with their standard. These indicators can result in deleterious effects on aquatic life in these bodies of water, as well as on those who use this water from the Bengalas river.
\end{abstract}

Key words: Ibuprofen, Bengalas river, pharmaceuticals.

\section{Introduction}

Pharmaceuticals, personal care products and illicit drugs have been considered as emerging environmental pollutants that persist in freshwater natural resources [1]. These organic pollutants enter the water systems from various sources such as human excretion (sewage), illicit disposal, landfill leakage, water drainage or industries [2]. Several studies report that these substances are present in low concentrations (ng/L, $\mu \mathrm{g} / \mathrm{L}$ ) and that the level of these compounds present in water can cause undesirable physiological effects, both in animals and humans, acting as endocrine disrupters [3].

The city of Nova Friburgo is in the mountainous region of the state of Rio de Janeiro and has a population of 150 thousand people. The municipality

Corresponding author: Robson Roney Bernardo, D.Sc., main research fields: environment, nanotechnology and pharmaceutical technology. of Nova Friburgo is bathed by the Rio Grande, Rio Bengalas, Ribeirao de Sao Jose and Captain and Rio Macae basins. The main rivers that cut the center of the city are the Saint Anthony river, Rio Canon and the Bengalas river, that forms after the meeting of these rivers. The city presents some hospitals and public health posts in which there are several standardized medications that are used by the population of the region and one of them is the ibuprofen [4].

Pharmaceuticals are known as chemicals of environmental concern due to health risks associated with exposure of aquatic life to these compounds and possible risks to human health when they reach drinking water, therefore, water sources should be monitored regularly [5]. Several authors have reported the occurrence of pharmaceutical residues in waters in Europe, Asia and the USA [6], but there is limited information about their occurrence in Brazil water bodies. 
Ibuprofen known as a non-steroidal anti-inflammatory drug has been widely used in the treatment of pain and inflammation in rheumatic disease and other disorders of skeletal muscle [7]. There is evidence that intrauterine exposure causes congenital malformation, such as cryptorchidism (absence of testis in the scrotal sac) and hypospadias (melting defect of the midline of the male ventral urethra) [8].

The objective of this study was to investigate the presence of ibuprofen in the Bengalas river, in the municipality of Nova Friburgo, state of Rio de Janeiro.

\section{Material and Methods}

\subsection{Sample Collection}

Samples of the waters of the Bengalas river were collected in the city of Nova Friburgo (RJ) at three points, named A (nascent; PT1 (Point 1)), B (inside the city; PT2) and C (final city; PT3), from October to December 2017. Afterwards, they were taken to the NUMPEX Laboratory of the Federal University of Rio de Janeiro, Campus Xerem, in Duque de Caxias. These were lyophilized (Liobras Model L101) with working temperature of $-55^{\circ} \mathrm{C}$.

\subsection{Sample Preparation}

The lyophilized residue was taken to the Radioisotope Laboratory Eduardo Pena Franco of the Federal University of Rio de Janeiro for the removal of interferents from the matrix, as well as the concentration and isolation of the analytes, solid phase extraction was performed using silica gel G60, 70-230 mesh $(2 \mathrm{~g})$ and solvent dichloromethane: hexane (1:1; $\mathrm{v} / \mathrm{v} ; 4 \mathrm{~mL})$. The resulting elute was slowly evaporated under nitrogen, yielding a solid residue which was resuspended in $1 \mathrm{~mL}$ of dichloromethane, then a $2 \mu \mathrm{L}$ aliquot transferred to a $100 \mathrm{~mL}$ volumetric flask, and dichloromethane was added until the volume of 100 $\mathrm{mL}$. From this solution, a $2 \mu \mathrm{L}$ aliquot was withdrawn, transferred to a $100 \mathrm{~mL}$ volumetric flask and the volume completed. At the end of the serial dilution, a $60 \mu \mathrm{L}$ aliquot was placed in the insert and vial for analysis.

\subsection{LC-MS (Liquid Chromatography with Mass Spectrometry): Detection of Ibuprofen}

Identification and quantification analysis of ibuprofen by mass-coupled high-performance liquid chromatography, Agilent 1200 series LC coupled to MS/MS quadrupole QTRAP $3200 \quad$ (Applied Biosystems). The chromatographic column used was $50 \times 2.1 \mathrm{~mm} \mathrm{C18} \mathrm{100A} \mathrm{(SilaChrom).} \mathrm{The} \mathrm{total} \mathrm{run}$ time was 40 minutes, with gradients being $95 \% \mathrm{H}_{2} \mathrm{O}$ and 5\% ACN (Acetonitrile) from 0 to $25 \mathrm{~min}, 10 \%$ $\mathrm{H}_{2} \mathrm{O}$ and $90 \% \mathrm{ACN}$ from 25 to $37 \mathrm{~min}, 95 \% \mathrm{H}_{2} \mathrm{O}$ and $5 \% \mathrm{ACN}$ from 37 to $40 \mathrm{~min}$, with an injection volume of $10 \mu \mathrm{L}$ and scanning at Q1 from 100 to $420 \mathrm{Da}$, positive mode.

\section{Results and Discussion}

The Bengalas river is the river that crosses the city of Nova Friburgo and has tributaries of Saint Anthony and Conego rivers and belongs to the basin of the Dois Rios river (Fig. 1). Twelve municipalities are located wholly or partially in the Dois Rios river basin: Bom Jardim, Cantagalo, Carmo, Cordeiro, Dois Barras, Itauco, Macuco, Nova Friburgo, Santa Maria Magdalena, Sao Sebastiao do Alto, Trajano de Moraes and Sao Fidelis [4].

Three points were established for the collection and analysis of ibuprofen from incoming waters that are part of the Bengalas river. The location coordinates were obtained with the aid of a compass, at PT1:

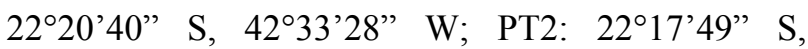

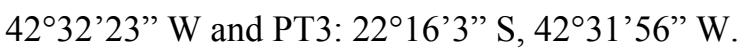

Anti-inflammatory ibuprofen has been extensively used in recent years, and although the elimination of this substance in wastewater treatment processes is greater than $90 \%$, the concentrations of ibuprofen and its metabolites that may be found in water may still be measurable receptors [9]. 


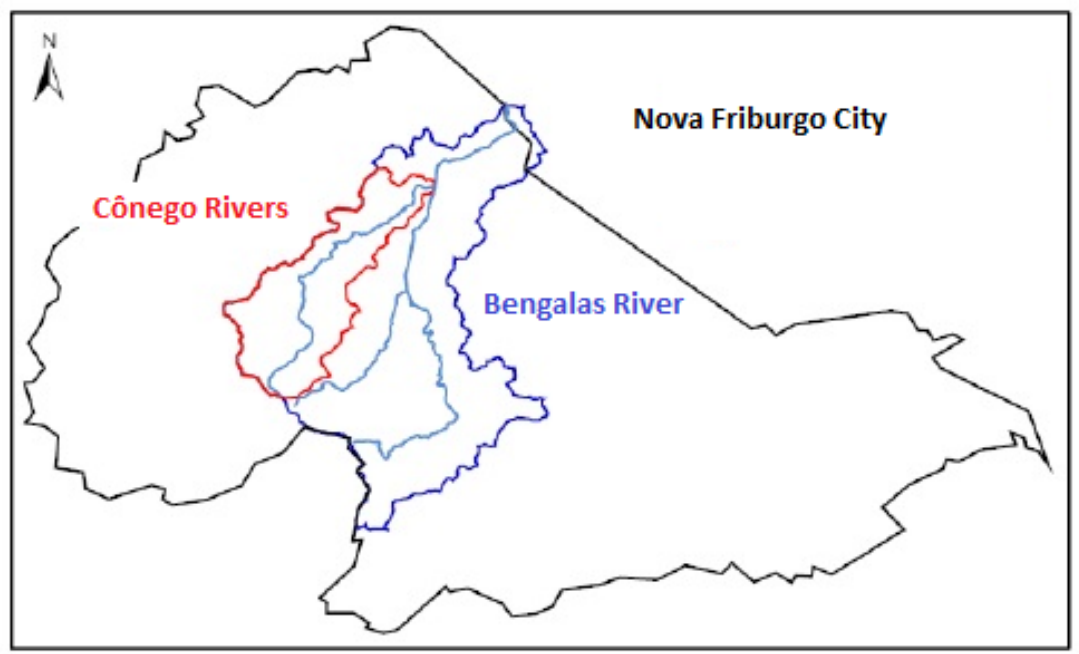

Fig. 1 Dois river basin map [4].

IBUPROFEN

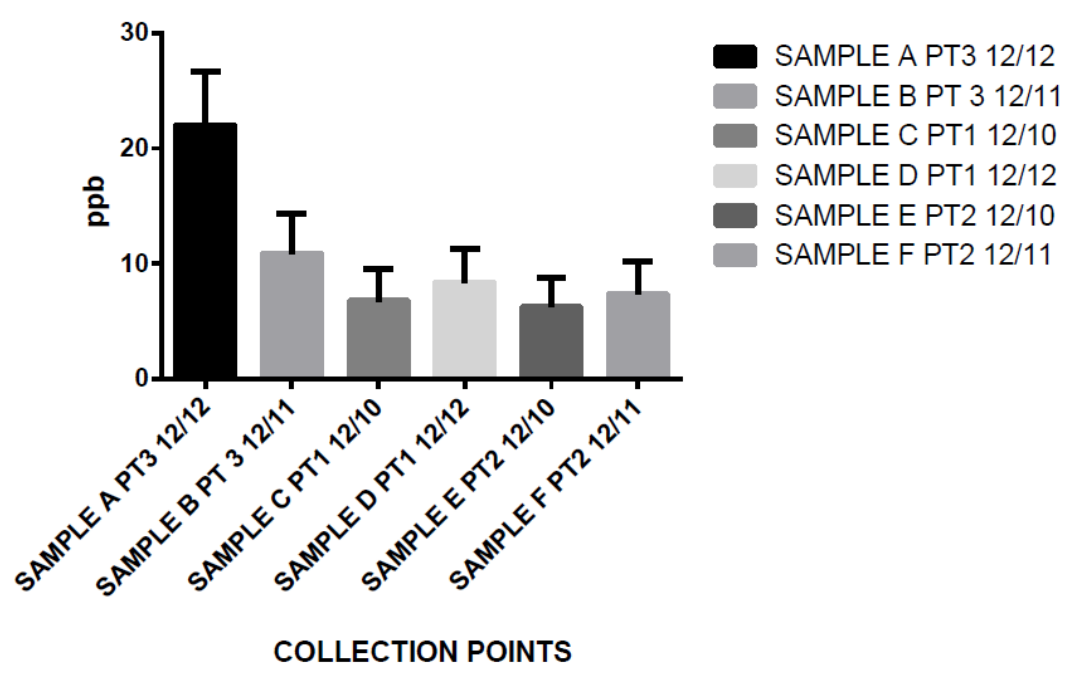

Fig. 2 Concentrations of samples in PT1, PT2 and PT3.

The total and maximum concentration of ibuprofen were verified at PT3 with approximately $20 \mathrm{ppb}$, describing the inability of wastewater treatment plants to remove complex pharmaceuticals as they were constructed with the main objective of removing carbon, nitrogen, phosphorus compounds and easily or moderately biodegradable microorganisms [10]. Fig. 2 shows the concentrations of ibuprofen in samples A, B, C, D, E and F.

Preliminary analyzes of the water collected along the Bengalas river showed the presence of ibuprofen and its metabolites, both phase I and phase II, according to Fig. 3. The mass spectrum reveals several ionic fragments, including the fraction of the metabolite derivative mono hydroxylated $(\mathrm{m} / \mathrm{z} 221$, Fig. 4), derived from ibuprofen phase I metabolism and the ion $\mathrm{m} / \mathrm{z} \mathrm{205}$, for ibuprofen molecule, as described by Brozinski, J. M., et al. [9].

The $\mathrm{m} / \mathrm{z}$ 161, 177 fragments correspond to derivate ions of $\mathrm{m} / \mathrm{z} 205$ and 221 respectively, according to the analysis performed by Brozinski, J. M., et al. [9] (Fig. 5). The ion $\mathrm{m} / \mathrm{z} 124$ corresponds to the ionic fragment referring to the precursor 312 , derived from the taurine conjugated metabolite of ibuprofen [11]. 


\section{IBUPROFEN}

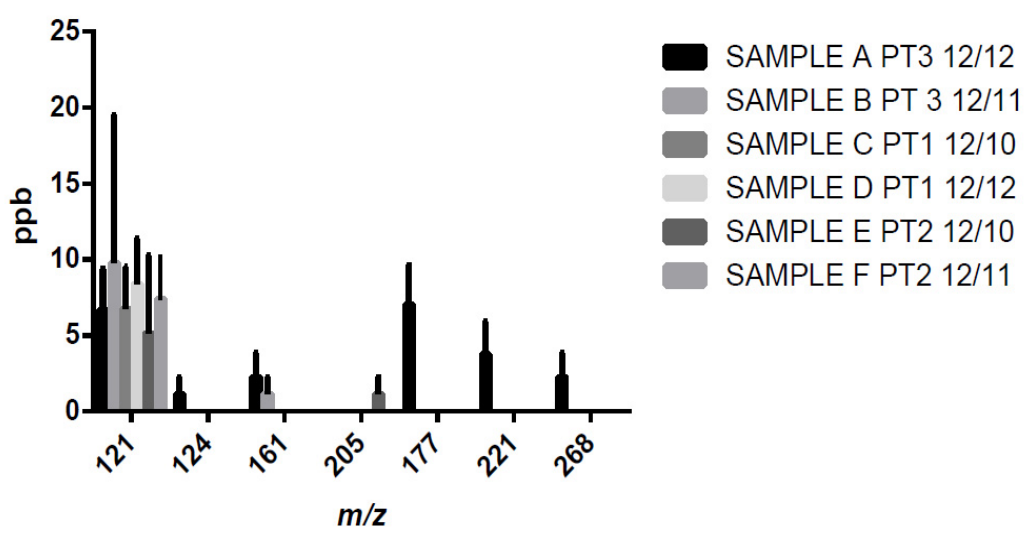

Fig. 3 Fragments of ibuprofen and their metabolites.<smiles>CC(C(=O)O)c1ccc(CC(C)(C)O)cc1</smiles>

$\mathrm{m} / \mathrm{z} 221$

Fig. 4 Metabolite derivative mono hydroxylated according to Brozinski, J. M., et al. [9].<smiles>C[14CH2]CCc1ccc(CC(C)C)cc1</smiles>

$\mathrm{C}_{12} \mathrm{H}_{17} \cdot$

161.133<smiles>CCc1ccc(CC(C)COC(=O)[C+](C)CC)cc1</smiles>

Fig. 5 Fragments correspond to the $\mathrm{m} / \mathrm{z} 161,177$. 


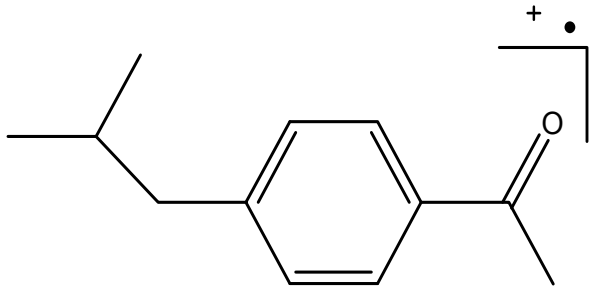

$\mathrm{m} / \mathrm{z} 177$

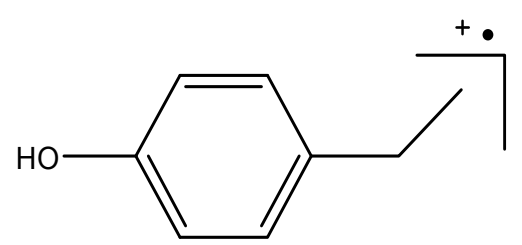

$\mathrm{m} / \mathrm{z} 121$

Fig. 6 The $\mathrm{m} / \mathrm{z} 121$ and 177 fragments may correspond to the oxidation products of ibuprofen [12].

According to studies by Zwiener, C. F. F. H. and Frimmel, F. H. [12], the m/z 121 and 177 fragments may correspond to the oxidation products of ibuprofen (Fig. 6).

\section{Conclusion}

The method was developed to study the presence of ibuprofen and its metabolites in aqueous samples, rivers and their tributaries and effluents, using the lyophilization process, solid phase extraction followed by LC-MS/MS analysis. Preliminary results showed that the concentrations of the pharmaceuticals and their metabolites can have a great impact on the ecosystem, as well as public health, considering that these substances can reach the river basins and even in low concentrations, can promote harmful health effects.

\section{Acknowledgment}

Thank CNPq for their support for project.

\section{References}

[1] Kasprzyk-Hordern, B., Dinsdale, R. M., and Guwy, A. J. 2009. "The Removal of Pharmaceuticals, Personal Care Products, Endocrine Disruptors and Illicit Drugs during Wastewater Treatment and Its Impact on the Quality of Receiving Waters." Water Research 43 (2): 363-80. doi:org/10.1016/j.watres.2008.10.047.

[2] Archer, E., Petrie B., Kasprzyk-Hordern, B., and Wolfaardt, G. M. 2017. "The Fate of Pharmaceuticals and Personal Care Products (PPCPs), Endocrine Disrupting Contaminants (EDCs), Metabolites and Illicit Drugs in a WWTW and Environmental Water." Chemosphere 174: 437-76. doi:10.1016/j.chemosphere.2017.01.101.

[3] Yan, O., Kim, H. L., Weon, J. I., and Seo, Y. R. 2015.
"Endocrine-Disrupting Chemicals: Review of Toxicological Mechanisms Using Molecular Pathway Analysis." Journal of Cancer Prevention 20 (1): 12-24. doi:10.15430/JCP.2015.20.1.12.

[4] Telles, W. R., Rodrigues, P. P. G. W., and Neto, A. J. S. 2016. "Automatic Calibration of a Simulator Applied to a Mountain River Using Experimental Precipitation and Level Data-Case Study: Corrego D'Antas, RJ.” Brazilian Journal of Water Resources 21 (1): 143-51. doi.org/10.21168/rbrh.v21n1.p143-151.

[5] Kummerer, K. 2010. "Pharmaceuticals in Enviroment." Annual Review of Environment and Resources 35 (1): 57-75. doi:org/10.1146/annurev-environ-052809-161223.

[6] Luo, Y., Guo, W., Ngo, H. H., Nghiem, D. L., Hai, F. I., Zhang, J., et al. 2014. "A Review on the Occurrence of Micropollutants in the Aquatic Environment and Their Fate and Removal during Wastewater Treatment." Science of the Total Environment 473: 619-41. doi:org/10.1016/j.scitotenv.2013.12.065.

[7] Magiera, S., and Gulmez, S. 2014. "Ultrasound-Assisted Emulsification Microextraction Combined with Ultra-high Performance Liquid Chromatography-Tandem Mass Spectrometry for the Analysis of Ibuprofen and Its Metabolites in Human Urine." Journal of Pharmaceutical and Biomedical 92: 193-202. doi.org/10.1016/j.jpba.2014.01.012.

[8] Kristensen, D. M., Mazaud-Guittot, S., Gaudriault, P., Lesne, L., Serrano, T., Main, K. M., et al. 2016. "Analgesic Use-Prevalence, Biomonitoring and Endocrine and Reproductive Effects." Natural Reviews $\begin{array}{llll}\text { Endocrinology } & 12 & \text { (7): } & 381-93 .\end{array}$ doi:10.1038/nrendo.2016.55.

[9] Brozinski, J. M., Lahti, M., Oikari, A., and Kronberg, L. 2013. "Identification and Dose Dependency of Ibuprofen Biliary Metabolites in Rainbow Trout." Chemosphere 93 (9): 1789-95. doi:org/10.1016/j.chemosphere.2013.06.018.

[10] Verlicchi, P., Al Aukidy, M., and Zambello, E. 2012. "Occurrence of Pharmaceutical Compounds in Urban Wastewater: Removal, Mass Load and Environmental Risk after a Secondary Treatment-A Review." Science of the Total Environment 429: 123-55. 
doi:org/10.1016/j.scitotenv.2012.04.028.

[11] Buser, H., Poiger, T., and Muller, M. D. 1999. "Occurrence and Environmental Behavior of the Chiral Pharmaceutical Drug Ibuprofen in Surface Waters and in Wastewater." Environmental Science \& Technology 33
(15): 2529-35. doi:10.1021/es981014w.

[12] Zwiener, C. F. F. H., and Frimmel, F. H. 2000. "Oxidative Treatment of Pharmaceuticals in Water." Water Research $34 \quad$ (6): 1881-5. doi:org/10.1016/S0043-1354(99)00338-3. 